
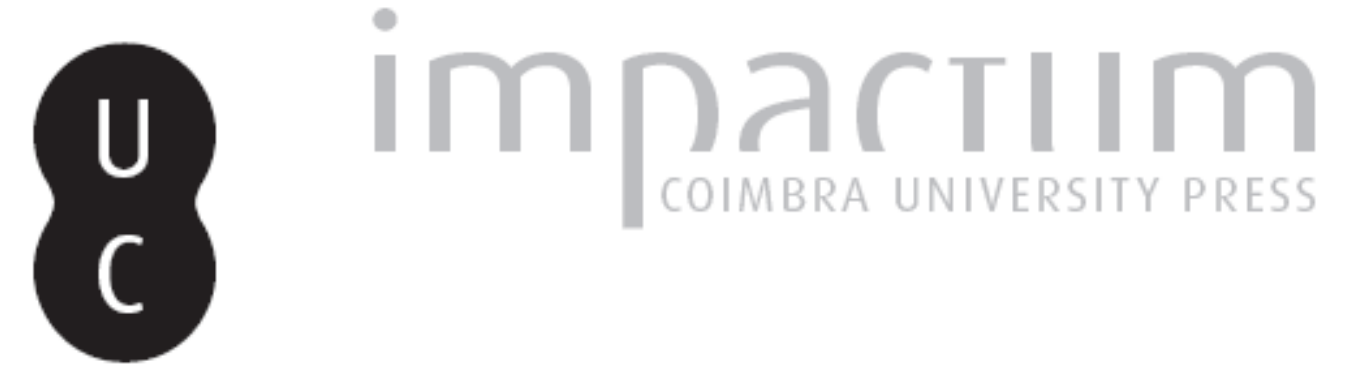

\title{
O físico Imanuel Bocarro Rosales: vestígios da sua presença em Livorno
}

\section{Autor(es): $\quad$ Silva, Sandra Neves}

Publicado por: Imprensa da Universidade de Coimbra

URL persistente:

URl:http://hdl.handle.net/10316.2/42447

DOI:

DOI:https://doi.org/10.14195/0870-8584_0_4

Accessed : $\quad$ 26-Apr-2023 12:19:34

A navegação consulta e descarregamento dos títulos inseridos nas Bibliotecas Digitais UC Digitalis, UC Pombalina e UC Impactum, pressupõem a aceitação plena e sem reservas dos Termos e Condições de Uso destas Bibliotecas Digitais, disponíveis em https://digitalis.uc.pt/pt-pt/termos.

Conforme exposto nos referidos Termos e Condições de Uso, o descarregamento de títulos de acesso restrito requer uma licença válida de autorização devendo o utilizador aceder ao(s) documento(s) a partir de um endereço de IP da instituição detentora da supramencionada licença.

Ao utilizador é apenas permitido o descarregamento para uso pessoal, pelo que o emprego do(s) título(s) descarregado(s) para outro fim, designadamente comercial, carece de autorização do respetivo autor ou editor da obra.

Na medida em que todas as obras da UC Digitalis se encontram protegidas pelo Código do Direito de Autor e Direitos Conexos e demais legislação aplicável, toda a cópia, parcial ou total, deste documento, nos casos em que é legalmente admitida, deverá conter ou fazer-se acompanhar por este aviso.

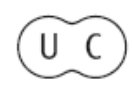




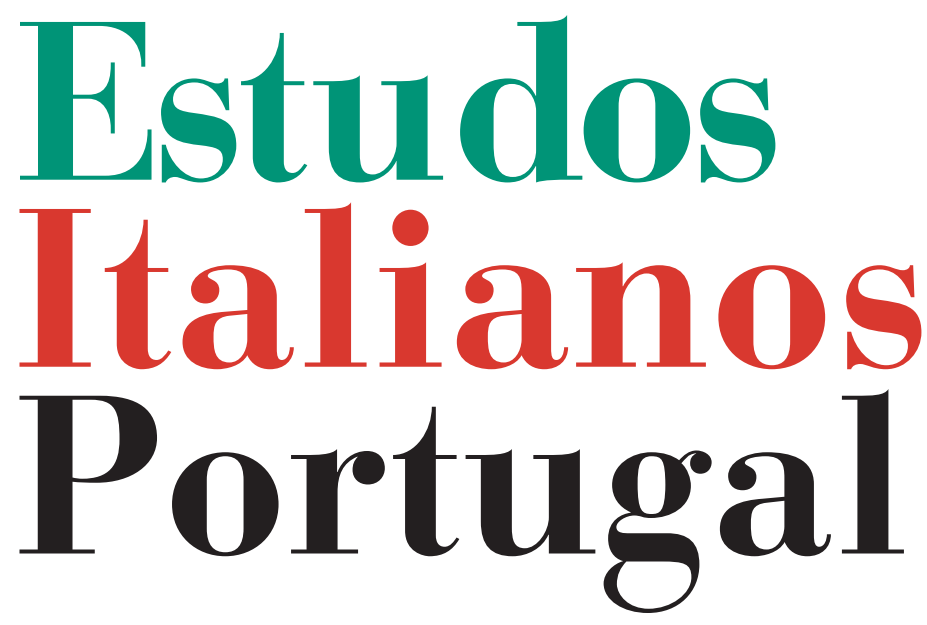

Instituto

Italiano

de Cultura

de Lisboa

Nova Série

$\mathrm{N}^{\mathbf{0}} \mathbf{0}$ 


\title{
O FÍSICO IMANUEL BOCARRO ROSALES: VESTÍGIOS DA SUA PRESENÇA EM LIVORNO
}

\author{
Sandra Neves Silva
}

ESPÍRITO ERUDITO E INSPIRADO, incessantemente entregue às letras e aos saberes de sua época, Imanuel Bocarro Rosales fora um insigne médico de Seiscentos que deixou ao mundo um notável legado escrito, fruto de intensa e douta reflexão, que se compõe de curiosos poemas encomiásticos, textos astronómico-matemáticos contendo ousadas condenações a Aristóteles (384/3 a.C-322 a.C), rasgados elogios à Lei de Moisés, opúsculos com predições sustentadas em cálculos estelares, versos tratando o Lapis Philosophorum dos alquimistas e composições heróicas consagradas aos destinos passados e vindouros de Portugal, as quais, achando-se pejadas de sentidos cifrados e de metáforas de tom sibilino e cabalizante, chegaram a contribuir para a reconfiguração do mito pátrio sebastianista.

Descendendo de cristãos-novos, ex-judeus forçados ao baptismo em 1497, Bocarro nascera em Lisboa, ${ }^{1}$ por volta de $1588,{ }^{2}$ tendo recebido nos primeiros tempos de vida uma rigorosa educação católica ao efectuar os seus estudos no

1 Assim o revela o próprio físico poeta que, no frontispício do seu Tratado dos Cometas que Appareceram em Novembro Passado de 1618, Lisboa, Pedro Craesbeeck, 1619, se apresenta como "Medico, \& Astrologo, natural desta cidade de Lisboa".

2 Numa missiva autógrafa de Junho de 1658, enviada ao Conde de Odemira, Bocarro confessa possuir setenta anos de idade, pelo que parece ter vindo ao mundo cerca de 1588: "V. S. perdoe meus attreujmentos que saõ ja de 70 . annos de idade, nos quais sempre fis bem, e seruj, e ja mais fis mal a nenhuã pessoa”. Cf. Biblioteca da Ajuda, Códice 50-V-36, fl. 146. 
colégio jesuíta de Santo Antão de Lisboa. Porém, ainda que imerso na vivência espiritual da Igreja reformada, ainda que mergulhado na cultura neo-escolástica, Bocarro, à semelhança de muitos outros cristãos-novos, não parecia comungar da devoção pelos Evangelhos, devendo antes estar afeiçoado ao Senhor do credo mosaico de seus antepassados, pois andava a judaizar às escondidas, alturas em que, ao que parece, convertera ao mosaísmo um seu irmão, se tratara a si mesmo como judeu, andara a desdenhar a fé católica, ao condenar o culto das imagens sagradas, ${ }^{3}$ e procurara celebrar algumas festividades prescritas na liturgia mosaica, de tal maneira que, cerca de 1611 ou 1612, na companhia de outros judaizantes, se dirigiu uma ou duas vezes em "Lisboa aos olivais pera a parte do grilo" para jejuar "aquelle dia que era o que chamaõ o jejum grande da saida do egipto que uem pello tempo da paschoa", ${ }^{4}$ ocasião em que parece ter lido e comentado de uma Bíblia algumas profecias tocantes à vinda do Messias prometido aos Hebreus.

Havendo cursado medicina em Alcalá de Henares e em Sigüenza, local onde obteve o grau de licenciado com grande ovação, Bocarro exerceu o múnus de físico no reino português ao mesmo tempo que se dedicava ao labor da pena, tendo publicado em 1624 a sua conhecida obra Anacephaleoses da Monarchia Luzitana, curiosa composição repartida em quatro fracções que, parecendo um hino de exaltação da

3 Bem como ao pronunciar expressões de descrença durante os ofícios pascais e comentar um livro profético das Santas Escrituras "por modos que erão contra a Lei de Christo”. Cf. IAN/TT, Inquisição de Lisboa, Caderno 9 do Promotor, fl. 437, apud Pedro de Azevedo, "O Bocarro Francês e os Judeus de Cochim e Hamburgo", in Archivo Historico Portuguez, tomo VIII, 1910, p. 186.

4 Cf. IAN/TT, Inquisição de Lisboa, Caderno 9 do Promotor, fl. 441, apud Pedro de Azevedo, "O Bocarro Francês e os Judeus de Cochim e Hamburgo"..., p. 188. Estas práticas judaizantes de Bocarro tratámos mais amiudadamente no nosso artigo "Criptojudaísmo e Profetismo no Portugal de Seiscentos: o Caso de Manoel Bocarro Francês alias Jacob Rosales (1588/93?-1662/68?)”, Estudos Orientais, vol. VIII, A Ideia de Felicidade no Oriente, Lisboa, 2003, pp. 173-174. 
união das coroas ibéricas (1580-1640), ao vaticinar Portugal como o último império dos tempos sob a égide de Filipe IV de Castela, era afinal um opúsculo de singular aspiração autonomista, o qual, de forma subtilmente velada e metafórica, apelava à independência do trono português do jugo de Espanha pela mão de um descendente de D. Sebastião (1554-1578) ligado à Casa de Bragança. ${ }^{5}$

Devido a tão arrojados intuitos autonomistas, que lhe custaram a animadversão dos Castelhanos e de certos poderosos, e talvez também pela chegada à Inquisição de Lisboa de uma denúncia do referido seu irmão apontando-o como judaizante, Bocarro teve de abandonar a sua pátria cerca de 1625, acabando por se ir estabelecer na "Nação» de judeus lusos de Hamburgo, comunidade onde, de alma e corpo, se converteu à ortodoxia rabínica, fazendo-se assim um "neo-judeu", pois que passara a envergar o nome de "esnoga" de Jacob Rosales, se submetera à cerimónia da circuncisão, rito imemorial do Povo Eleito, frequentara os templos judaicos, recitando as preces mosaicas do Amidá e do Semá Israel, e exercera a tarefa de predicante da Lei de Moisés, altura em que "ensinaua as ceremonias da ley explicando os lugares da escritura conforme a interpretaçaõ dos sabios". ${ }^{6}$ A par de tudo isto, Bocarro também se empenhara em realizar as cerimónias do Sabat, ocasiões decorridas aos Sábados, à boca da noite, em que, na intimidade de seu lar, como "patrão da caza" e tendo junto de si os seus parentes mais chegados (esposa, filho, algum irmão ou irmã), costumava retirar de um armário "huá caixa afeiçaõ das de marmellada em que estaua crauos nos moscada, pimenta e gengibre", 7 especiarias que benzia com umas pala-

5 Uma síntese de parte das ideias proféticas de Bocarro acha-se no nosso artigo acima citado, páginas 175-183.

${ }^{6}$ Cf. IAN/TT, Inquisição de Lisboa, Processo n. ${ }^{\circ} 7276$, de Miguel Francês, Sessão de 5 de Maio de 1646, fl. 22.

7 Cf. IAN/TT, Inquisição de Lisboa, Processo n. ${ }^{\circ}$ 3020, de Gaspar Bocarro, Sessão de 18 de Outubro de 1641, fls. 42v-43. 
vras em hebraico e depois cheirava e dava a cheirar aos demais, recolhendo-as de seguida no mesmo armário de onde extraía um copo com cerveja, a qual também benzia com outros vocábulos e bebia e dava a beber aos presentes, vertendo no chão a que remanescia. ${ }^{8}$

Tendo passado mais de vinte anos na Alemanha, onde prosseguira o seu labor de clínico e dilatara a sua obra escrita, Bocarro, nos derradeiros anos de sua vida, algures em 1652 ou 1653, resolveu deixar aquele país para se ir instalar em terras italianas, atitude que tomara movido por um ignoto estímulo, segundo o que contara numa epístola endereçada ao Conde de Odemira em Junho de 16589: “eu estaua em Hamburgo com riqueza e dignidades, como pode testemunhar Duarte nunes de Acosta, e os Menistros de S. Magestade que alli foraõ; mas naõ sej que estimolo me moueo que con grande instançia pus toda minhas forças em liçençiarme daj, atte que o alcansej, perdendo quasi toda minha fazenda, que estimo em pouco E uindo a esta Italia”. ${ }^{10}$ Ora nesta «Itália», em que viria a ser requisitado por "muitos Principes", ${ }^{11}$ Bocarro resolveu estabelecer-se na toscana urbe de Livorno, precisamente no "bairro onde uiuem os professores da (...) Ley de Moyses", ${ }^{12}$ costumando frequentar a santa "esnoga" da cidade, conforme noticiaram no Palácio da Inquisição de Lisboa, no citado ano de 1658, dois religiosos portugueses, sendo um deles o cónego de Évora Gregório de Pina, que contou ter visto Bocarro, ${ }^{13}$ "medico e Astrologo muito no-

8 Ibidem..., fl. 43.

9 Trata-se da mesma carta referida na nota 2.

${ }^{10}$ Cf. Biblioteca da Ajuda, Códice 50-V-36, fl. 145v.

11 Ibidem.

12 Cf. IAN/TT, Inquisição de Lisboa, Caderno 35 do Promotor, fl. 352v.

13 Ao referir-se a Bocarro, o cónego Gregório enganou-se no seu nome próprio, pois, ao invés de Manoel, chamou-o João Bocarro Rozalles. Cf. Ibidem..., fl. 352, apud Pedro de Azevedo, "A Inquisição e Alguns Seiscentistas”, in Archivo Historico Portuguez, vol. III, p. 1905, p. 462. 
meado neste Reyno", ${ }^{14}$ sentado no templo mosaico como os demais postulantes da crença de Israel; e o outro o cónego da Sé de Coimbra Manoel dos Reis de Carvalho, o qual declarou que o "doutor Rosalles (...) grande mathematico que imprimio Livros", se achara na sinagoga de Livorno com "insignias de judeo", ${ }^{15}$ isto é, com uma espécie de "diuisa branca sobre os ombros o que (...) chamaõ mantos que (...) chega ate o meio dos brassos". ${ }^{16}$

Curiosamente, parece que Bocarro chegou a manter algumas conversas com os ditos clérigos, ${ }^{17}$ momentos em que, vindo a confessar que era judeu profitente do credo mosaico e que "daria conta de sy a Deus e que elle e os mais judeos hiaõ bem", ${ }^{18}$ deixou transparecer uma íntima pecularidade da sua fé, a de que aceitava que a mensagem do Nazareno resgatava igualmente as almas pecadoras, pois "tinha para sy que os que seguiaõ a Ley de Cristo se saluauaõ tambem", ${ }^{19}$ além de que sempre nutrira "grande Conceito da pessoa de Cristo" e "naõ hauia duuida que o Papa era uerdadeiro Vigario de Cristo e da Igreja." 20

Judeu tolerante para com a fé dos cristãos, Bocarro, enquanto habitara a portuária cidade de Livorno, deslocara-se várias vezes a Florença, tendo frequentado a corte dos Médicis, lugar onde conseguiu atrair atenções e divulgar parte dos seus eruditos escritos, ao publicar o seu Fasciculus Trium Verarum Propositionum, compilação que, saída em 1654, na tipografia de Francisci Honuphrij, na dita cidade de Flo-

14 Cf. IAN/TT, Inquisição de Lisboa, Caderno 35 do Promotor, fl. 352.

15 Ibidem..., fl. 356v.

16 Ibidem..., fl. 355v.

17 Por duas vezes, na rua, com Gregório de Pina, e por muitas vezes com Manoel dos Reis de Carvalho. Cf. IAN/TT, Inquisição de Lisboa, Caderno 35 do Promotor..., fls. 353 e 356v.

18 Ibidem..., fl. 356v.

19 Ibidem..., fl. 353, apud Pedro de Azevedo, "A Inquisição e Alguns Seiscentistas"..., p. 463.

${ }^{20}$ Ibidem..., fl. 356v, apud Ibidem. 
rença, era dirigida ao ainda imberbe herdeiro da Etrúria Cosmo III (1642-1723), consistindo na reimpressão de três obras de Rosales, a primeira, de pendor astronómico, denominada Vera Mundi Compositio, a segunda, de feição astrológica, intitulada Foetus Astrologici, e a terceira, de teor filosófico, designada Carmen Intellectuale. ${ }^{21}$ Mas além de frequentar as esferas áulicas dos Médicis, onde devia ter brilhado com a sua citada compilação, Bocarro, por meio de correspondência epistolar, também mantinha algum contacto com várias figuras da governança de Portugal, gentes de sua pátria a quem, munido dos estudos das estrelas, ia assegurando diversos sucessos políticos, nomeadamente a manutenção da autonomia da coroa portuguesa e o triunfo dos lusos nas guerras travadas com Espanha a seguir à Restauração de Portugal em 1640. Ora vejamos:

Defendendo a causa lusitana, Bocarro escreveu de Livorno ao Conde de Odemira, D. Francisco de Faro e Noronha, presidente do Conselho Ultramarino português, a atrás referida missiva de Junho de 1658, à qual acrescentou uma "Proposicaõ de que o Reino de Portugal se sustentarâ debaxo do dominio Portuges, Descendente do senhor Don João .4. que Deus tem", ${ }^{22}$ exposição onde, postulando que a Lusitânia se não sujeitará de novo a Castela, antes permanecerá sob o domínio português da Casa de Bragança, aponta vários motivos que anunciam a preservação da independência lusa, sendo eles já a justiça divina, que restituíu aos portugueses o seu ceptro, há tantos anos usurpado, e que "naõ falta na conseruaçaõ do que assi justamente ordenou, e restitujo igualandose isto. a sua diujna Prouidençia",23 já o céu e as luzes dos astros, que externamente mostraram a separação

21 Antes da reimpressão em 1654, no Fasciculus Trium Verarum Propositionum, a Vera Mundi Compositio fora publicada em 1622, a Foetus Astrologici em 1626 e 1644 e a Carmen Intellectuale em 1639.

22 Reproduzimos esta mesma "Proposicaõ" no final do artigo.

23 Cf. Biblioteca da Ajuda, Códice 50-V-36, fl. 147. 
da Lusitânia de Espanha, "denotada no Nacimento delRej don Felipe o .4. E estabelecida nelRej don Joaõ o 4. e em sua semente, com a felicidade do Reino", ${ }^{24}$ já a acção política, visível tanto na esfera interna, com a nobreza e todo o povo português a emergirem naturalmente invencíveis, por se acharem "muj constantes na defensaõ de sua Patria", 25 como no xadrez internacional, com o trono lusitano a se dever empenhar em estabelecer um matrimónio régio com o reino de França, preservar uma sólida aliança com Inglaterra, senhora dos mares, e formular um conserto medíocre com a Holanda, até que se cumpra o prognóstico que diz que "castella hade conceder a Portugal, a paz que aos estados unidos, conheçendo a seu Rej". ${ }^{26}$

Além da epístola ao Conde de Odemira, Bocarro escreveu, em Maio de 1659, na cidade de Livorno, uma missiva ao diplomata português Francisco de Sousa Coutinho, ${ }^{27}$ na qual, parecendo continuar convicto da manutenção da autonomia lusa, deixou transcorrer a ideia de que havia predito o feliz sucesso das Linhas de Elvas, célebre batalha ocorrida a Janeiro do citado ano de 1659 em que os portugueses, procurando aniquilar o imponente cerco castelhano à dita localidade de Elvas, conseguiram vencer os espanhóis com grande retumbância, forçando-os a uma célere retirada. ${ }^{28}$ E de ressaltar, curiosamente, que Sousa Coutinho, ex-embaixador de Portugal em Roma, parecia nutrir vasta admiração

${ }^{24}$ Ibidem..., fls. 147-147v.

25 Ibidem..., fl. $147 \mathrm{v}$.

${ }^{26}$ Ibidem..., fl. 147 bis.

27 Desta carta apenas conhecemos cópias, uma existente na Biblioteca da Ajuda, Códice 51-VI-1, fls. 72-72v, contendo um erro do nome do autor, visto que em vez de Manoel, vem Francisco Bocarra Francez; e a outra na Biblioteca Pública de Évora, Códice CV/1-6, fls. 195v-196, a qual veio a ser publicada por João Lúcio de Azevedo, A Evolução do Sebastianismo, Lisboa, Editorial Presença, 1984, pp. 145-146.

${ }^{28}$ Sobre esta batalha, veja-se António Paulo David Duarte, Linhas de Elvas - 1659 - Prova de Força, Lisboa, Tribuna da História, 2003. 
pelos vaticínios de Bocarro, dado que, numa missiva que enviou ao rei luso D. João IV (1640-1656) em 1649, onde aspirava a convencer tal monarca a casar a sua filha D. Joana com Carlos II de Inglaterra, mencionou e transcreveu uma predição de Bocarro sobre a Grã-Bretanha, depositando nela profunda confiança e dando a entender que era proveitoso acreditar em seu autor, pois "tem este homem fallado tanto ao certo em nossas couzas, que pode obrigar a que o creamos em outras". ${ }^{29}$ Tal predição, que constitui a derradeira parte da oitava 91 da referida obra Anacephaleoses da Monarchia Luzitana, é composta pelos seguintes versos: "Aquella, a quem de Anglia a aura alenta,/Do pertinaz error jà penitente,/Por meyo conuertida de hua Infanta,/Nesta conquista irà da terra Santa". ${ }^{30}$

Passado menos de um mês de mandar a dita epístola a Sousa Coutinho, Bocarro enviou, de Livorno, mais uma missiva, desta vez a um bispo de Portugal de identidade desconhecida, a quem continuou a glosar a ideia de pleno triunfo e libertação da Lusitânia em relação a Espanha, recorrendo a sugestivas comparações. Equivalendo o acima referido feito vitorioso de Elvas e a «milagrosa» batalha de Ourique em tempo de D. Afonso Henriques (1128-1185), alega então que, no resguardo e defesa de seu reino, o luso é senhor do castelhano, facto que a experiência mostra e as estrelas "haõ constituido", 31 pois um soldado português enfermo, roto e desnudo afigura-se elefante, tigre e leão ao mais temido espanhol; na verdade, da mesma forma que a

29 Cf. Correspondência Diplomática de Francisco de Sousa Coutinho Durante a sua Embaixada em Holanda, publ. por Edgar Prestage e P. M. Laranjo Coelho, vol. III, 1648-1650, Lisboa, Centro Tipográfico Colonial, 1955, p. 302. Veja-se também Durval Pires de Lima, Francisco de Sousa Coutinho, Lisboa, Tipografia da Editorial Império, 1943, pp. 28-29.

30 Cf. Manoel Bocarro Francês, Anacephaleoses da Monarchia Luzitana, Lisboa, Antonio Aluarez, 1624, fl. 20.

31 Cf. Biblioteca da Ajuda, Códice 50-V-36, fl. 148. 
natureza deu à ovelha o temor do lobo, assim deu ao castelhano o receio do luso, que é seu leão e tigre, de modo que almejar sujeitar o trono de Portugal a Espanha é algo contra-natura e que naturalmente se não pode alcançar, pelo que o melhor para o bem e conservação de Castela é aceitar que o ceptro lusitano a assista, não como submetida, mas sim como igual; ${ }^{32}$ em suma, quem desejar a felicidade ao trono espanhol que se interponha pela paz daquele com Portugal, já que este reino "lhe sera melhor amigo, que sogeito". ${ }^{33}$

Apologeta da plena independência do ceptro lusitano, Bocarro, ainda na mesma epístola ao bispo, deixou transparecer que mantinha um certo contacto com a Casa Real portuguesa, pois, além de ter pedido ao jovem rei lusitano D. Afonso VI (1656-1667) seis onças de âmbar, almíscar e calambuco, drogas finíssimas e aromáticas para usar na preparação do seu cachundé, ${ }^{34}$ uns graõzinhos que se trazem na boca para lhe comunicar um agradável hálito, ainda andou a burilar os "Naçimentos Reais", 35 juízos astrológicos da monarquia lusitana onde deve ter incluído o do referido monarca D. Afonso VI, soberano que, a seu ver, devendo viver um futuro de paz e triunfo no reino de Portugal, iria emergir como "hum (...) grande Rej", ${ }^{36}$ imbuído de um destino metafísico ligado ao achamento da "Ilha Encoberta", local onde "se uiue como os Antiguos Patriarcas", ${ }^{37}$ situado algures nos domínios lusitanos, e que constitui a morada do já citado D. Sebastião, monarca português perdido na trágica batalha de Alcácer Quibir em 1578. ${ }^{38}$

32 Ibidem..., fls. 148-148v.

33 Ibidem..., fl. 148v.

34 Ibidem.

35 Cf. Biblioteca da Ajuda, Códice 50-V-36, fl. 148v.

36 Ibidem..., fl. 146.

37 Ibidem..., fl. $145 \mathrm{v}$.

38 “aquelle Bendito Rey, que se imagina auer morto em Africa, está oje na Ilha encuberta (...) E algum dia se manifestará que o tem Deus guardado alli, para muito seruiço seu". Ibidem..., fl. 145. 
Embrenhado nas causas lusitanas, Bocarro ia assim, por meio de correspondência epistolar, mantendo algum contacto à distância com a sua terra de origem. Mas ao mesmo tempo que cultivava tal contacto, a vida em Itália chamava-o a outros assuntos, de forma que, como pio judeu público, ingressou em 1660 na associação de beneficiência mosaica «Hebra de Cazar Orfas» de Livorno. ${ }^{39}$

Por aquela altura, contava mais de setenta anos de vida, devendo morar perto de sua irmã Rachel Rosales, também judia pública na "esnoga" livornina, e de seu cunhado Custódio Lobo, negociante e trovador. Sem prejuízo de sua avançada idade, continuara a dedicar-se à ocupação de médico, sendo que fora nessa qualidade que, algures em 1662 ou 1668, foi chamado a Florença para tratar da Duqueza de Strozzi. Nesta ocasião, por razões desconhecidas, acabaria por vir a falecer, ${ }^{40}$ podendo os seus restos mortais ter ficado a jazer em Livorno, cidade que habitou nos últimos anos que vivera. Terminava assim, em solo italiano, a vida de um notável português, que incansavelmente privara com príncipes, nobres, diplomatas e eruditos, se entregara de alma viva ao judaísmo rabínico e se votara ao mundo dos saberes e da escrita, nela fazendo constar, como vimos, arrebatados juízos estelares sobre os governos e destinos da sua pátria lusitana.

39 Cf. Cecil Roth, Notes sur les Marranes de Livourne, Paris, Imp. H. Elias, 1931, p. 14 , nota 3.

${ }^{40}$ Cf. Diogo Barbosa Machado, Bibliotheca Luzitana, Historica, Critica e Cronologica, tomo III, Lisboa, Officina Ignacio Rodrigues, 1972, p. 197. 


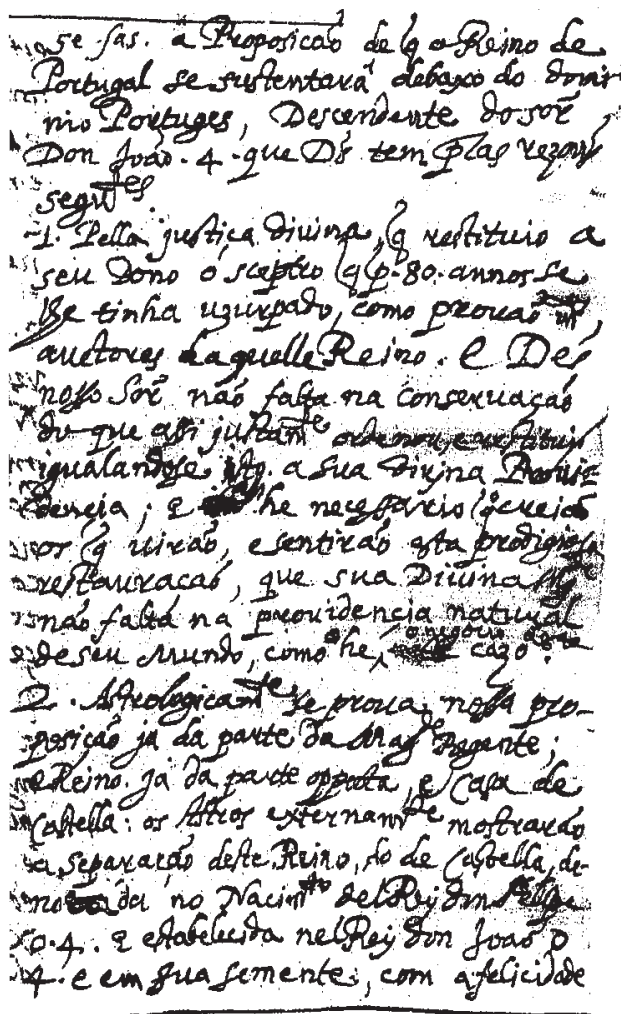

Manuscrito autógrafo de Bocarro redigido em Livorno no ano de 1658 (BA, 50-V-36, fls. 147-147bis) 
76 Sandra Neves Silva

So Reino progropticedo two tio.1Anaughateos is da nonaretriafusitan imprefs no anno he 1624 . etein ria esplicacas, SUI pequena no. ann de 2626.2 nos 3 lines to

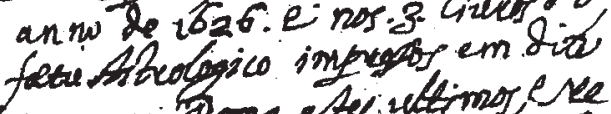
anne en hona sterimetere extampasos noutras party. 2 efos

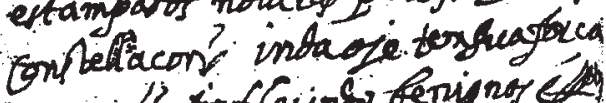
en val sisfluino benynos em Poutigal, stion gue de Ceol

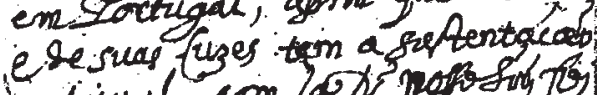
natival, com (o o noto suljo) - recuido alefocovello

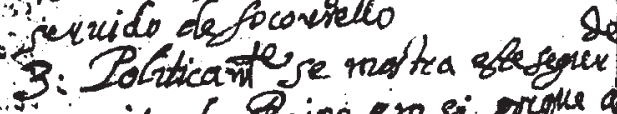
vejpeito do Arino insij prigue a STabreja Delle, etodo oporlo esa

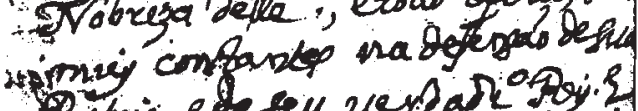

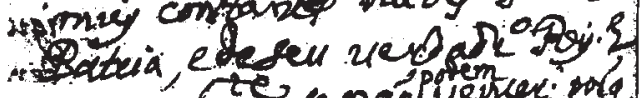

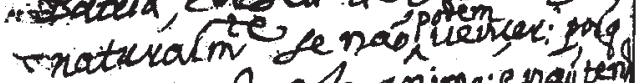
sicongerugns of animo; enaiten sirtemor do Contracio, des ralem (nt)

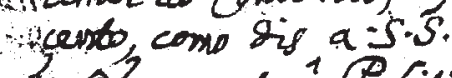

- 4.0 quanto 1 Politica extect - a ecliaritica seste vencer as migo ex. R com mansis particuly

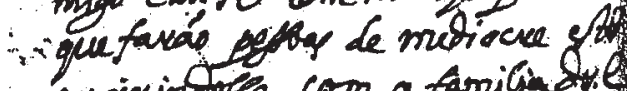

- engixinogfe com a famiand

- em vegulos, delgostas suedly th xocitafie, Coxunle ost on

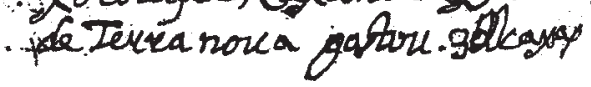


147 \&it.

quath; couts ogeto suba adianefese

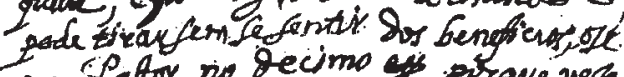

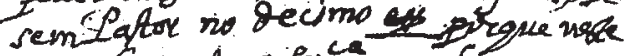
cos. he cexta a $\mathrm{Sn}_{1}$ quedry. Nonexa ciede mifiplacantroningeg;

PCacater donis hyitu issedots

$$
\text { Deorg3 }
$$

Mas he necefario saber dax, come quand, aguern, eforguetr.

S. abe Tranca se eftaglecertic im och jament de.S. A. ese configuined, sobennge tratar.

6. a fe Inglaterxa he ope ayojo, porg

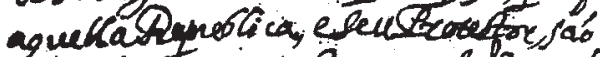

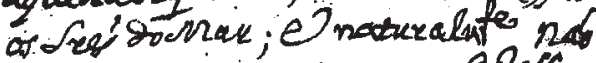
podern viver én paz cone ghella, e comven \& ate Scino, or latar on fekzeir amioor.

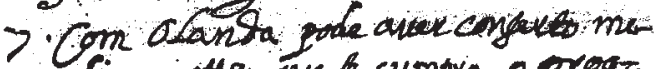
diocre atte grefe cumpin o grog notico que 2ys. I que cabelia hase concider a Portigal, a paz que as estolos unit, conrecensiv a fell Ary ath 